\title{
hag expression in Bacillus subtilis is both negatively and positively regulated by ScoC
}

\author{
Prashant Kodgiret and K. Krishnamurthy Rao
}

Correspondence

Prashant Kodgire

pkodgire@bsd.uchicago.edu

Received 3 July 2008

Revised 18 September 2008

Accepted 29 September 2008

\author{
School of Biosciences and Bioengineering, Indian Institute of Technology Bombay, Powai, Mumbai \\ 400076, India
}

\begin{abstract}
In Bacillus subtilis, motility and chemotaxis require the expression of hag, which encodes flagellin. This gene is transcribed by the $\sigma^{\mathrm{D}}$ form of RNA polymerase and is regulated by a group of proteins called transition state regulators (TSRs). Our studies show that hag transcription is negatively regulated by the transition state regulator $\mathrm{ScoC}$, by binding to its promoter. Furthermore, ScoC, indirectly, also positively regulates hag by increasing the availability of $\sigma^{\mathrm{D}}$ by downregulating the levels of the anti- $\sigma^{\mathrm{D}}$-factor FlgM. We further show that the positive regulation by ScoC predominates over the negative regulation.
\end{abstract}

\section{INTRODUCTION}

In Bacillus subtilis, the hag gene, which codes for flagellin, the structural protein of flagella, is transcribed by the $\sigma^{\mathrm{D}}$ dependent RNA polymerase (Mirel \& Chamberlin, 1989; Ordal et al., 1993). This gene is transcribed as a monocistronic mRNA and shows a temporal pattern of expression that peaks at the end of the exponential phase of growth followed by a decrease in transcript levels as sporulation proceeds (Mirel et al., 2000). In general, temporal regulation of many genes involved in post-exponential-phase processes such as motility, chemotaxis, extracellular enzyme synthesis and sporulation is coordinated by regulatory proteins called transition state regulators (TSRs) such as AbrB, ScoC and SinR (Smith, 1993; Strauch et al., 1989). Regulation of genes is also brought about by the interplay of sigma factors with their cognate anti-sigma factors (Hecker \& Volker, 1998; Helmann, 1999; Hughes \& Mathee, 1998). For example, in B. subtilis, the motility genes are transcribed at the postexponential phase of growth by the $\sigma^{\mathrm{D}}$ form of RNA polymerase. Until then, $\sigma^{\mathrm{D}}$ is kept sequestered by the anti- $\sigma^{\mathrm{D}}$ factor, FlgM; it is subsequently released to transcribe the motility genes (Helmann, 1999; Hughes \& Mathee, 1998; Mirel et al., 1994). FlgM inhibits the activity of $\sigma^{\mathrm{D}}$ RNA polymerase by the sequestration of $\sigma^{\mathrm{D}}$ and also by destabilizing the existing $\sigma^{\mathrm{D}} \sim$ holoenzyme (Bertero et al., 1999; Helmann, 1999; Hughes \& Mathee, 1998). The transition state regulator $\mathrm{ScoC}$ is a negative regulator of protease production and sporulation that binds to a consensus DNA sequence, 5'-RATANTATY-3' (Henner et al., 1988; Kallio et al., 1991; Perego \& Hoch, 1988). ScoC has also been reported to be a positive regulator of motility genes

tPresent address: Department of Molecular Genetics and Cell Biology, University of Chicago, Chicago, IL 60637, USA.

Abbreviations: EMSA, electrophoretic mobility shift assay; NBT/BCIP, nitro blue tetrazolium/5-bromo-4-chloro-3-indolyl phosphate.
(Caldwell et al., 2001), which are mainly transcribed by the $\sigma^{\mathrm{D}}$-dependent RNA polymerase (Ordal et al., 1993). This conclusion has been derived from the transcription profiling of $s c o C$ mutant cells ( $s c o C 4$ ), which showed that most of the motility genes, including hag, are transcribed at lower levels in the scoC mutant as compared to that in the wild-type (Caldwell et al., 2001). We were thus interested in understanding the regulation of hag by ScoC.

\section{METHODS}

Bacterial strains, plasmids and growth conditions. Bacterial strains and plasmids used in this study are listed in Table 1. Escherichia coli $\mathrm{DH} 5 \alpha$ was used as an intermediate host for plasmid constructions using standard cloning techniques (Sambrook et al., 1989). Both E. coli DH5 $\alpha$ and B. subtilis cells were grown at $37^{\circ} \mathrm{C}$ in LB medium unless specified otherwise. Transformations in B. subtilis were performed using the protoplast transformation protocol (Bron, 1990). Where necessary, antibiotics were added to the following final concentrations: for B. subtilis, chloramphenicol, kanamycin and spectinomycin were at 5,10 and $100 \mu \mathrm{g} \mathrm{ml}^{-1}$, respectively; for E. coli, ampicillin was at $100 \mu \mathrm{g} \mathrm{ml}^{-1}$.

PCR. PCRs were carried out using either 100 pg plasmid DNA or 2 ng genomic DNA as template. The PCRs were performed in a reaction volume of $50 \mu \mathrm{l}$, with 5 units of Taq DNA polymerase and 50 pmol of each primer in buffer supplied by the manufacturer (MBI Fermentas). The PCRs contained a final concentration of $1.5 \mathrm{mM} \mathrm{MgCl}_{2}$ and $200 \mu \mathrm{M}$ of each dNTP. In general, the PCR was performed for 30 cycles with an initial denaturation step at $95{ }^{\circ} \mathrm{C}$ for $5 \mathrm{~min}$ and a final extension step at $72{ }^{\circ} \mathrm{C}$ for $10 \mathrm{~min}$. The temperature and time for the denaturation, annealing and extension steps varied depending on the form of DNA, the $T_{\mathrm{m}}$ of the primers used and the length of the target sequence; the conditions used for each primer pair are mentioned in the plasmid construction paragraphs below. Oligonucleotides (Table 2) were synthesized at Microsynth AG, Balgach, Switzerland.

\section{Plasmid constructions}

Construction of pMhag'-lacZ. A 549 bp DNA fragment ( -188 to +361 from the transcription start of hag) containing the promoter 
Table 1. Plasmids and strains used in this study

\begin{tabular}{|c|c|c|}
\hline Plasmid/strain & Description or genotype ${ }^{\star}$ & Source or reference $\dagger$ \\
\hline \multicolumn{3}{|l|}{ Plasmids } \\
\hline pMUTIN4 & $\begin{array}{l}\text { Integration vector designed for systematic inactivation of coding } \\
\text { sequences and for analysis of unknown gene's promoter expression } \\
\text { pattern via the } \beta \text {-galactosidase reporter }\end{array}$ & BGSC (Vagner et al., 1998) \\
\hline pRB381 & $\begin{array}{l}\text { E. coli-Bacillus replicative, multi-copy vector for translational fusion } \\
\text { with the } \beta \text {-galactosidase gene, 'lacZ, } \mathrm{Km}^{\mathrm{r}} \mathrm{Ap}^{\mathrm{r}}\end{array}$ & BGSC (Bruckner, 1992) \\
\hline pMhag'-lacZ & $\begin{array}{l}\text { pMUTIN4 bearing a } 549 \text { bp insert }(-189 \text { to }+360) \text { containing hag } \\
\text { promoter and first } 90 \text { codons of hag ORF fused with lacZ }\end{array}$ & This study \\
\hline phag-lacZ & $\begin{array}{l}\text { pRB381 bearing a } 361 \text { bp insert }(-189 \text { to }+172) \text { of hag promoter region } \\
\text { containing H1 }\left(5^{\prime} \text {-GATATTAAT- } 3^{\prime}\right) \text { and H2 }\left(5^{\prime} \text {-CACAATATT- } 3^{\prime}\right) \text {, rbs } \\
\text { and first } 27 \text { codons of hag ORF fused with the lac }\end{array}$ & This study \\
\hline phag-lacZ- $\mathrm{H}_{\mathrm{P}}$ & phag-lacZ with $\mathrm{H}_{\mathrm{P}}\left(5^{\prime}\right.$-GATATAGGG-3') & This study \\
\hline \multicolumn{3}{|l|}{ B. subtilis strains } \\
\hline 168 & $\operatorname{trpC2}$ & BGSC \\
\hline 168 : hag'-lacZ & 168 with $h^{\prime} g^{\prime}$-lacZ chromosomal integration & This study \\
\hline $168:$ hag' $^{\prime}$ lacZ/pIC-scoC & 168 : hag'-lacZ bearing pIC-scoC & This study \\
\hline 168/phag-lacZ & 168 bearing phag-lacZ & This study \\
\hline 168/phag-lacZ- $\mathrm{H}_{\mathrm{P}}$ & 168 bearing phag-lacZ- $\mathrm{H}_{\mathrm{P}}$ & This study \\
\hline 168/phag-lacZ- $\mathrm{H}_{\mathrm{Q}}$ & 168 bearing phag-lacZ- $\mathrm{H}_{\mathrm{Q}}$ & This study \\
\hline 168/pflgM-lacZ & 168 bearing pflgM-lacZ & This study \\
\hline JH642 & $\operatorname{trp} C 2$ pheA1 & BGSC \\
\hline JH642/phag-lacZ & JH642 bearing phag-lacZ & This study \\
\hline $1 \mathrm{~A} 764$ & JH642 flgM $\Delta 80$ & BGSC (Mirel et al., 1994) \\
\hline
\end{tabular}

${ }^{\star} \mathrm{Km}^{\mathrm{r}}$, kanamycin resistance; $\mathrm{Ap}^{\mathrm{r}}$, ampicillin resistance; $\mathrm{Sp}^{\mathrm{r}}$, spectinomycin resistance; $\mathrm{Cm}^{\mathrm{r}}$, chloramphenicol resistance. Mutated nucleotides are shown in bold.

$\nmid$ BGSC, Bacillus Genetic Stock Center.

and the first 90 codons of the hag ORF (Mirel \& Chamberlin, 1989) was PCR amplified from genomic DNA of B. subtilis 168 with primers KKR211 and KKR212 (Table 2) $\left(95{ }^{\circ} \mathrm{C} / 1 \mathrm{~min}, 40{ }^{\circ} \mathrm{C} / 1 \mathrm{~min}, 72{ }^{\circ} \mathrm{C} /\right.$ $40 \mathrm{~s}$ ) and fused in translational frame to the E. coli lacZ gene, at the HindIII and BamHI sites, in the integrative plasmid pMUTIN4 (Table 1) (Vagner et al., 1998) to give pMhag'-lacZ (Table 1).

Construction of $\mathbf{H}_{\mathbf{A}}$ in pBluescript $\mathbf{S K}+$. To create the mutated $\mathrm{H} 1$ site, $\mathrm{H}_{\mathrm{A}}$ (5'-CCGCTGCAG-3'), two PCR products were obtained from pMhag'-lacZ with primers KKR211/KKR293 $\left(95^{\circ} \mathrm{C} / 1 \mathrm{~min}\right.$, $42{ }^{\circ} \mathrm{C} / 1 \mathrm{~min}, 72{ }^{\circ} \mathrm{C} / 30 \mathrm{~s}$ ) and KKR292/KKR212 (Table 2) $\left(95{ }^{\circ} \mathrm{C} /\right.$ $1 \mathrm{~min}, 40{ }^{\circ} \mathrm{C} / 1 \mathrm{~min}, 72{ }^{\circ} \mathrm{C} / 30 \mathrm{~s}$ ). The first product was digested with HindIII and PstI and cloned into pBluescript SK + . The second PCR product was digested with PstI and BamHI and cloned downstream of the first PCR product to give pBluescript $\mathrm{SK}+$ containing $\mathrm{H}_{\mathrm{A}}$. The mutation in $\mathrm{H}_{\mathrm{A}}$ was confirmed by Pst $\mathrm{I}$ digestion as this site was introduced in the primers to create the mutation. This recombinant plasmid was used as template to amplify $\mathrm{H}_{\mathrm{A}}$ with primers KKR113/ KKR114 (Table 2) $\left(95^{\circ} \mathrm{C} / 1 \mathrm{~min}, 40{ }^{\circ} \mathrm{C} / 1 \mathrm{~min}, 72{ }^{\circ} \mathrm{C} / 20 \mathrm{~s}\right)$ for electrophoretic mobility shift (EMSA) studies.
Construction of $\mathbf{H}_{\mathbf{Q}}$ in pBluescript $\mathbf{S K}+$. To create the mutated $\mathrm{H} 2$ site, $\mathrm{H}_{\mathrm{Q}}$ (5'-CGGCCCGGG-3'), two PCR products were obtained from pMhag'-lacZ with primers KKR211/KKR322 $\left(95{ }^{\circ} \mathrm{C} / 1 \mathrm{~min}\right.$, $42{ }^{\circ} \mathrm{C} / 1 \mathrm{~min}, 72{ }^{\circ} \mathrm{C} / 30 \mathrm{~s}$ ) and KKR321/KKR212 (Table 2) $\left(95{ }^{\circ} \mathrm{C} /\right.$ $1 \mathrm{~min}, 40^{\circ} \mathrm{C} / 1 \mathrm{~min}, 72{ }^{\circ} \mathrm{C} / 30 \mathrm{~s}$ ). The first product was digested with HindIII and SmaI and cloned into pBluescript SK + . The second PCR product was digested with $S m a \mathrm{I}$ and $\mathrm{BamHI}$ and cloned downstream of the first PCR product to give pBluescript $\mathrm{SK}+$ containing $\mathrm{H}_{\mathrm{Q}}$. The mutation in $\mathrm{H}_{\mathrm{Q}}$ was confirmed by digestion with $S m a \mathrm{I}$ as this site was introduced in the primers to create the mutation. This recombinant plasmid was used as template to amplify $\mathrm{H}_{\mathrm{Q}}$ with primers KKR292/ KKR320 (Table 2) $\left(95^{\circ} \mathrm{C} / 1 \mathrm{~min}, 46{ }^{\circ} \mathrm{C} / 1 \mathrm{~min}, 72{ }^{\circ} \mathrm{C} / 20 \mathrm{~s}\right)$ for EMSA studies.

Construction of phag-lacZ. To construct phag-lacZ, a DNA fragment of $361 \mathrm{bp}(-189$ to +172$)$ containing the hag promoter and the first 27 codons of the hag ORF (Mirel \& Chamberlin, 1989) was PCR amplified from pMhag'-lacZ (Table 1) with primers KKR211/ KKR337 (Table 2) $\left(95{ }^{\circ} \mathrm{C} / 1 \mathrm{~min}, 42{ }^{\circ} \mathrm{C} / 1 \mathrm{~min}, 72{ }^{\circ} \mathrm{C} / 30 \mathrm{~s}\right)$. The amplified product was digested with $\mathrm{HindIII/BamHI}$ and fused in 
Table 2. Primers used in this study

\begin{tabular}{|c|c|c|}
\hline Primer & Sequence $\left(5^{\prime}-3^{\prime}\right)^{*}$ & Restriction site $\dagger$ \\
\hline KKR113 & GCGTCGACGGATTTTTTTATTTTTGT & SalI \\
\hline KKR114 & GCAGGATCCCACATTGTTTTGTTCCT & BamHI \\
\hline KKR211 & GTGAAGCTTGAAATTGACGCCCCA & HindIII \\
\hline KKR212 & CGC $\overline{\text { GGATCCAACACGTTGAAGGAT }}$ & BamHI \\
\hline KKR262 & CGTGTCGACCAGGACTATTCGTAGGC & SalI \\
\hline KKR292 & CCGCTGCAGGATGTAGCCGGGAGG & Pst $\mathrm{I}$ \\
\hline KKR293 & GATCTGCAGCGGGGATTGTCTCTGATTTTG & Pst $\mathrm{I}$ \\
\hline KKR296 & CCAAAGCTTCACTTCGCAGCCCGCTG & HindIII \\
\hline KKR306 & GGAGGATCCATCTTTTTTTCTCCTTATTAG & BamHI \\
\hline KKR307 & CCAGTCGACGGTACCCCTTCTATGCGC & SalI \\
\hline KKR311 & GCATATTCATATGAAAATCAATCAATTTGG & NdeI \\
\hline KKR312 & GCATCTCGAGTTGCTTTTTATAAAAATTAATC & XhoI \\
\hline KKR320 & CGTGGATCCGTTGTTTGAAGACAAACG & BamHI \\
\hline KKR321 & CGACCCGGGGCAGCGCTTAACACACTG & SmaI \\
\hline KKR322 & CGTCCCGGGCCGGTTAATTCTCATTGTTTT & SmaI \\
\hline KKR327 & GCTCCCGGGGATGTAGCCGGGAGG & SmaI \\
\hline KKR328 & TATATCGGATTGTCTCTGATTTTGTTAAT & \\
\hline KKR337 & GCAGGATCCATGTTCTTTTGGCTCGCACT & BamHI \\
\hline
\end{tabular}

${ }^{\star}$ Nucleotides in bold are complementary to the genome sequence.

$\dagger$ Underlined in the corresponding sequence.

translational frame to the $E$. coli lacZ gene in the replicative multicopy plasmid pRB381 (Bruckner, 1992) to give phag-lacZ (Table 1). Plasmid pRB381 is derived from plasmid pUB110 (Bruckner, 1992) and the copy number of pUB110 in B. subtilis is about 50 per chromosome (Bron, 1990).

Construction of phag-lacZ- $\mathbf{H}_{\mathbf{p}}$. To create $\mathrm{H}_{\mathrm{P}}\left(5^{\prime}\right.$-GATATAGGG-3'), in which the $3^{\prime}$-end of $\mathrm{H} 1$ was mutated, two PCR products were obtained from pMhag'-lacZ with primers KKR327/KKR212 $\left(95{ }^{\circ} \mathrm{C} /\right.$ $1 \mathrm{~min}, 40{ }^{\circ} \mathrm{C} / 1 \mathrm{~min}, 72{ }^{\circ} \mathrm{C} / 30 \mathrm{~s}$ ) and KKR211/KKR328 (Table 2) $\left(95{ }^{\circ} \mathrm{C} / 1 \mathrm{~min}, 42{ }^{\circ} \mathrm{C} / 1 \mathrm{~min}, 72{ }^{\circ} \mathrm{C} / 30 \mathrm{~s}\right)$. The first product was digested with $\mathrm{SmaI}$ and BamHI and cloned into pBluescript SK+. The second PCR product was digested with HindIII and cloned upstream of the first PCR product to give $\mathrm{H}_{\mathrm{P}}$ in pBluescript $\mathrm{SK}+$. The latter was used as the template to reamplify the hag promoter containing the $\mathrm{H}_{P}$ site with primers KKR211/KKR337 (Table 2) and cloned in translational fusion with lac $Z$ in $\mathrm{pRB} 381$ to give phag-lacZ$\mathrm{H}_{\mathrm{P}}$ (Table 1). pBluescript $\mathrm{SK}+$ carrying $\mathrm{H}_{\mathrm{P}}$ was also used to amplify $\mathrm{H}_{\mathrm{P}}$ with primers KKR113/KKR114 (Table 2) for EMSA with ScoC.

Construction of phag-lacZ- $\mathrm{H}_{\mathrm{Q}}$. The hag promoter containing the $\mathrm{H}_{\mathrm{Q}}$ site was amplified from the recombinant pBluescript SK+ plasmid carrying $\mathrm{H}_{\mathrm{Q}}$ (described above) with primers KKR211/KKR337 and cloned in translational fusion with lacZ in pRB381 to give phag-lacZ$\mathrm{H}_{\mathrm{Q}}$ (Table 1).

Construction of pflgM-lacZ. A 151 bp DNA fragment $(-106$ to +45 from the transcription start of $y v y F)$ containing the $\mathrm{P}_{\mathrm{D}-1}$ promoter and the ATG of $y v y F$ (Mirel et al., 1994) was PCR amplified from genomic DNA of B. subtilis 168 with primers KKR296/KKR306 (Table 2) $\left(95{ }^{\circ} \mathrm{C} / 1 \mathrm{~min}, 48{ }^{\circ} \mathrm{C} / 1 \mathrm{~min}, 72{ }^{\circ} \mathrm{C} / 20 \mathrm{~s}\right)$, digested with HindIII and $B a m H I$ and fused in translational frame with the E. coli lacZ gene in pRB381 to give plasmid pflgM-lacZ (Table 1).

Construction of pIC-scoC. A $1.65 \mathrm{~kb}$ DNA fragment containing the promoter, ORF and transcription terminator of $\operatorname{scoC}$ (Perego \& Hoch, 1988) was amplified from genomic DNA of B. subtilis 168 with primers KKR262/KKR307 (Table 2) $\left(95{ }^{\circ} \mathrm{C} / 1 \mathrm{~min}, 48^{\circ} \mathrm{C} / 1 \mathrm{~min}\right.$, $72{ }^{\circ} \mathrm{C} / 1 \mathrm{~min} 40 \mathrm{~s}$ ) and cloned at the Sall site in plasmid pIC56 (copy no. 10) (Steinmetz \& Richter, 1994) to give pIC-scoC (Table 1).

Assay for $\boldsymbol{\beta}$-galactosidase in $\boldsymbol{B}$. subtilis. The strains were grown at $37{ }^{\circ} \mathrm{C}$ in Penassay broth to stationary phase $\left(\mathrm{OD}_{600} \sim 2.0\right)$ and the $\beta$ galactosidase activities were determined (Nicholson \& Setlow, 1990). All the $\beta$-galactosidase assays presented in this work were performed in triplicate. The activities presented are the mean of triplicate values. At least three independent experiments were performed and a representative result is shown. We ensured that the lac $Z$ results were not due to differences in copy numbers between the various strains. We compared the copy number of pRB381-derived plasmids by dotblots, which were very similar in all the strains (data not shown).

Electrophoretic mobility shift assay. EMSA was performed as described in the Roche gel shift manual (http://www.roche-appliedscience.com/pack-insert/3353591a.pdf). End-labelling of the probe was carried out with digoxigenin-11-ddUTP (DIG-ddUTP) using terminal transferase in $20 \mu \mathrm{l}$ reaction buffer containing $0.2 \mathrm{M}$ potassium cacodylate, $0.25 \mathrm{M}$ Tris/HCl, $\mathrm{pH} 6.6,0.25 \mathrm{mg} \mathrm{BSA} \mathrm{m}^{-1}$ and $5 \mathrm{mM}$ $\mathrm{CoCl}_{2}$ at $37{ }^{\circ} \mathrm{C}$ for $15 \mathrm{~min}$, and then $2 \mu \mathrm{l} 0.2 \mathrm{M}$ EDTA (pH 8.0) was added to terminate the reaction. Binding reactions were carried out with $10 \mathrm{nM}$ DIG-labelled probe and ScoC $(1 \mu \mathrm{M})$ in $20 \mu \mathrm{l}$ reaction buffer containing $20 \mathrm{mM}$ HEPES, $\mathrm{pH}$ 7.6, $1 \mathrm{mM}$ EDTA, $10 \mathrm{mM}\left(\mathrm{NH}_{4}\right)_{2} \mathrm{SO}_{4}$, $1 \mathrm{mM}$ DTT, Tween $20(0.2 \%$, w/v), $30 \mathrm{mM} \mathrm{KCl}, 1 \mu \mathrm{g}$ poly $(\mathrm{dI}-\mathrm{dC})$, and $0.1 \mu \mathrm{g}$ poly-L-lysine at $37{ }^{\circ} \mathrm{C}$ for $15 \mathrm{~min}$. For the competition reaction, protein was first incubated in presence of 100 -fold molar excess of competitor DNA (unlabelled specific DNA) followed by incubation with the labelled probe. The bound product was electrophoresed on a $5 \%$ polyacrylamide gel in $0.25 \times$ Tris/borate/EDTA buffer at $4{ }^{\circ} \mathrm{C}$. The gel was electroblotted onto a nylon membrane and treated with antiDIG-alkaline phosphatase conjugate. DNA was detected with nitro blue tetrazolium/5-bromo-4-chloro-3-indolyl phosphate (NBT/BCIP) in AP buffer (100 mM Tris/HCl, pH 9.5, $\left.100 \mathrm{mM} \mathrm{NaCl}, 5 \mathrm{mM} \mathrm{MgCl}_{2}\right)$ until visible bands were observed. 
Cloning, expression and purification of FlgM, and raising of anti-FIgM antibodies. The gene coding for FlgM (Mirel et al., 1994) was PCR amplified from genomic DNA of B. subtilis 168 with primers KKR311/KKR312 (Table 2) $\left(95{ }^{\circ} \mathrm{C} / 1 \mathrm{~min}, 45{ }^{\circ} \mathrm{C} / 1 \mathrm{~min}, 72{ }^{\circ} \mathrm{C} / 30 \mathrm{~s}\right)$ and cloned into plasmid pET28a (Novagen) at the NdeI and XhoI sites to give pFlgM. The cloning strategy was designed to provide a His-tag at the $\mathrm{C}$ terminus of the protein. pFlgM was transformed into E. coli BL21(DE3) and FlgM was induced with $0.1 \mathrm{mM}$ IPTG. E. coli $\mathrm{BL} 21(\mathrm{DE} 3) / \mathrm{pFlgM}$ was inoculated in $5 \mathrm{ml} \mathrm{LB}$ broth and grown overnight at $37{ }^{\circ} \mathrm{C}$ in an orbital shaker at 200 r.p.m. Then $50 \mu$ of the overnight grown culture was used to inoculate $5 \mathrm{ml}$ fresh LB broth. The culture was grown at $37{ }^{\circ} \mathrm{C}$ in an orbital shaker at 200 r.p.m. for $2.5 \mathrm{~h}$, until the $\mathrm{OD}_{600}$ reached $0.5-0.6$. Freshly prepared IPTG was added to a final concentration of $0.1 \mathrm{mM}$ and incubation continued for $40 \mathrm{~min}$. Rifampicin was added to a final concentration of $150 \mu \mathrm{g}$ $\mathrm{ml}^{-1}$ and incubation continued for $2.5 \mathrm{~h}$. Cells were harvested by centrifugation and the pellet was washed with $1 \mathrm{ml}$ buffer containing $25 \mathrm{mM}$ Tris/ $\mathrm{HCl}, \mathrm{pH}$ 7.4. The pellet was resuspended in $500 \mu \mathrm{l}$ buffer containing $25 \mathrm{mM}$ Tris/ $\mathrm{HCl}, \mathrm{pH}$ 7.4, and cells were lysed by lysozyme treatment at $30{ }^{\circ} \mathrm{C}$ for $15 \mathrm{~min}$, followed by sonication at $4{ }^{\circ} \mathrm{C}$. The cell lysate was centrifuged to separate supernatant and pellet and samples were analysed by SDS-PAGE (data not shown).

FlgM was affinity purified from the supernatant on a Ni-NTA resin as described in the Qiagen Ni-NTA spin kit manual. Input sample was prepared in $50 \mathrm{mM}$ phosphate buffer, $\mathrm{pH} 8.0,0.3 \mathrm{M} \mathrm{NaCl}$ and $10 \mathrm{mM}$ imidazole and loaded on a spin column. The column was washed with the above buffer containing $100 \mathrm{mM}$ imidazole (six column volumes). The protein sample was eluted with $150 \mu \mathrm{l}$ buffer containing $1 \mathrm{M}$ imidazole. Samples were analysed by SDS-PAGE to determine purity and recovery of the protein. The purified protein, which showed a single band with purity greater than $95 \%$ (data not shown), was used for raising polyclonal anti-FlgM antibodies in rabbits (by Bangalore Genei, Bangalore, India).

We tested the ability of the anti-FlgM antibodies to detect FlgM in extracts of B. subtilis 168 . The cells were grown at $37^{\circ} \mathrm{C}$ for $6 \mathrm{~h}$ and the presence of FlgM was tested by Western blot analysis (Sambrook et al., 1989) with the anti-FlgM antibodies. A single band of $\sim 10 \mathrm{kDa}$ was clearly detected in wild-type cells that was missing in the flgM mutant 1A764 (Mirel et al., 1994), in which 80 of the 88 amino acids have been deleted (see Fig. 4A).

Western blot analysis of FlgM. Equal number of cells, corresponding to $\mathrm{OD}_{600} \sim 3.0$, of B. subtilis 168 and 168 scoC strains from an overnight culture were seeded into $25 \mathrm{ml}$ Penassay broth and grown with shaking at $37{ }^{\circ} \mathrm{C}$. The growth rates of both strains were identical. Samples $(5 \mathrm{ml})$ corresponding to equal numbers of cells were harvested at $5 \mathrm{~h}\left(t_{1}\right)$ and $6 \mathrm{~h}\left(t_{2}\right)$ relative to $t_{0}(4 \mathrm{~h}$ of growth; time of entry into stationary phase) and centrifuged. The pellet was heated at $95{ }^{\circ} \mathrm{C}$ for $15 \mathrm{~min}$ in $30 \mu \mathrm{l} \mathrm{SDS}$-loading buffer, loaded onto a $15 \%$ SDS-polyacrylamide gel and electroblotted onto a nitrocellulose membrane. The membrane was probed with rabbit anti-FlgM antibodies (raised against purified FlgM; see above); bands were detected using an alkaline phosphatase-linked secondary antibody and NBT/BCIP (Sambrook et al., 1989).

\section{RESULTS}

\section{hag is negatively regulated by ScoC}

To study the involvement of ScoC in the transcription of hag, a 549 bp DNA fragment $(-188$ to +361 from the transcription start site of hag) containing the hag promoter and the first 90 codons of the hag ORF (Mirel \&
Chamberlin, 1989) was fused to the E. coli lacZ gene in an integrative plasmid, pMUTIN4 (Vagner et al., 1998), to give pMhag'-lacZ (Table 1) and transformed into B. subtilis 168 and $168 \mathrm{scoC}$, a $s c o C$ disruptant (Kodgire et al., 2006), to yield 168: hag'-lacZ and 168scoC: hag'-lacZ (Table 1). The strains were grown with shaking at $37{ }^{\circ} \mathrm{C}$ in Penassay broth to stationary phase $\mathrm{OD}_{600} \sim 2.0$ ) and the $\beta$ galactosidase activities were determined (Nicholson \& Setlow, 1990). We observed an almost twofold increase in the hag promoter activity in $168 \mathrm{scoC}$ : hag'-lacZ (435 \pm 15 Miller units) as compared to that in wild-type $(225 \pm 10$ Miller units) (Table 3A), indicating that ScoC negatively regulates hag transcription. This result was in contrast to that observed from the transcription profiles of $B$. subtilis 168 and scoC4, which demonstrated decreased hag transcription in scoC4 (Caldwell et al., 2001).

To determine if the negative regulation of hag by ScoC is due to a direct binding of ScoC to the hag promoter region (Mirel \& Chamberlin, 1989), we searched for putative ScoC binding sites using BioEdit (http://www.mbio.ncsu.edu/ BioEdit/bioedit.html). This search revealed the presence of two sites located between -11 and $-2\left(\mathrm{H1}, 5^{\prime}-\right.$ GATATTAAT- $\left.3^{\prime}\right)$ and between +103 and $+112\left(\mathrm{H} 2,5^{\prime}\right.$ CACAATATT-3') (Fig. 1) with an 8/9 and 7/9 match with the consensus ScoC binding site (5'-RATANTATY-3'), respectively (Caldwell et al., 2001). The H1 site overlaps with the -10 region of the bipartite hag promoter and the $\mathrm{H} 2$ site is located in the hag ORF (Fig. 1). We therefore tested the ability of ScoC to bind to these sites by EMSA.

\section{ScoC binds to the hag promoter region}

Binding reactions were carried out with $1 \mu \mathrm{M}$ ScoC and a $150 \mathrm{bp}$ DNA probe $(10 \mathrm{nM})$ containing either the $\mathrm{H} 1$ or $\mathrm{H} 2$ site. The two probes were obtained by PCR amplification from pMhag'-lacZ with primers KKR113/KKR114 and

Table 3. hag reporter expression in B. subtilis strains

\begin{tabular}{|lc|}
\hline Strains & $\begin{array}{c}\boldsymbol{\beta} \text {-Galactosidase activity } \\
\text { (Miller units) }\end{array}$ \\
\hline A & \\
$168:$ hag' $^{*}$-lacZ & $225 \pm 10$ \\
168scoC: hag'-lacZ & $435 \pm 15$ \\
168: hag'-lacZ/pIC-scoC & $410 \pm 20$ \\
B & \\
168/phag-lacZ & $2000 \pm 50$ \\
168/phag-lacZ-H & $16500 \pm 150$ \\
168/phag-lacZ-H & $17000 \pm 150$ \\
C & \\
JH642/phag-lacZ & $1700 \pm 25$ \\
1A764/phag-lacZ & $3700 \pm 50$ \\
\hline
\end{tabular}

*The $\beta$-galactosidase assays were performed as described in Methods. The activities shown are the mean of triplicate values. At least three independent experiments were performed and a representative result is shown. 


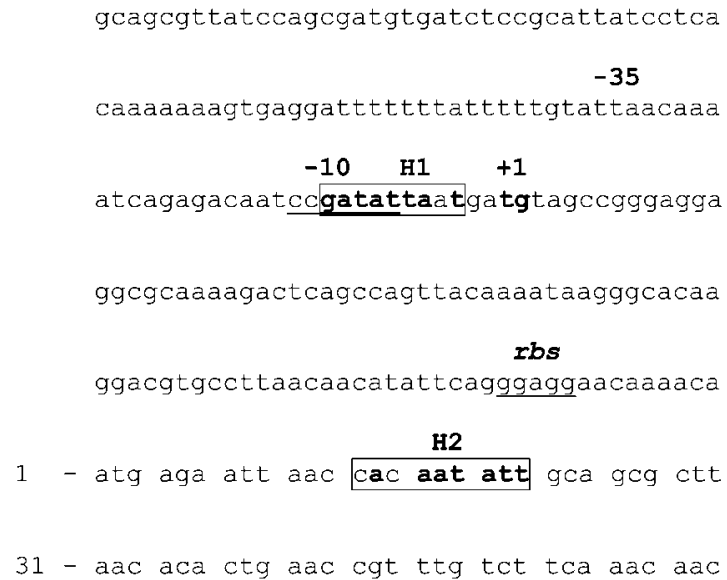

Fig. 1. Sequence of the hag promoter region (Mirel \& Chamberlin, 1989) and location of ScoC binding sites. ScoC binding sites $\mathrm{H} 1$ and $\mathrm{H} 2$ are indicated by the boxed nucleotides. Nucleotides in bold in these sites are identical to the ScoC consensus sequence, 5'-RATANTATY-3' (Caldwell et al., 2001). +1 denotes the transcription start site. The -10 sequence $\left(5^{\prime}\right.$-ccgatat- $\left.3^{\prime}\right)$, the -35 sequence and ribosome-binding site ( $r b s)$ are underlined.

KKR292/KKR320, respectively (Table 2). Fig. 2(A, B) shows that both the DNA probes, containing the $\mathrm{H} 1$ and $\mathrm{H} 2$ sites respectively, were retarded in the presence of ScoC (lane 2) as compared to in its absence (lane 1). The retardation was significantly reduced with a 100 -fold molar excess of unlabelled probe (lane 3 ), showing the specificity of binding. Thus, we conclude that ScoC is capable of binding to both the sites in the hag promoter region.

To further confirm the specificity of binding of ScoC to $\mathrm{H} 1$ and $\mathrm{H} 2$, we mutated $\mathrm{H} 1$ and $\mathrm{H} 2$ to $\mathrm{H}_{\mathrm{A}}$ (5'-CCGCTGCAG- $\left.3^{\prime}\right)$ and $\mathrm{H}_{\mathrm{Q}}$ (5'-CGGCCCGGG-3'), respectively, and then performed the EMSA with ScoC. The hag promoter containing the mutated $\mathrm{H} 1\left(\mathrm{H}_{\mathrm{A}}\right)$ or mutated $\mathrm{H} 2\left(\mathrm{H}_{\mathrm{Q}}\right)$ sites was amplified from pBluescript $\mathrm{SK}+$ carrying either $\mathrm{H}_{\mathrm{A}}$ or $\mathrm{H}_{\mathrm{Q}}$ with primers KKR113/KKR114 and KKR292/ KKR320, respectively, and used as probes for the binding experiments. Fig. 2(A, B), lane 4 shows that mutation of either of the ScoC binding sites significantly reduced the binding of ScoC to the hag promoter region. Furthermore, the mutated probes could not compete for binding of ScoC to the respective wild-type probes (Fig. 2A, B, lane 5), indicating that $\mathrm{H} 1$ and $\mathrm{H} 2$ are bona fide binding sites for ScoC. Thus, our results are strongly in support of a direct transcriptional regulation of hag by ScoC.

\section{Mutation of the $\mathrm{H} 1$ or $\mathrm{H} 2$ site in the hag promoter region relieves repression}

To investigate whether mutation of either the $\mathrm{H} 1$ or $\mathrm{H} 2$ site led to relief from repression, we made three constructs, phag-lacZ, phag-lacZ- $\mathrm{H}_{\mathrm{P}}$ and phag-lacZ- $\mathrm{H}_{\mathrm{Q}}$ (Table 1), carrying the wild-type hag promoter and mutated $\mathrm{H} 1$ and $\mathrm{H} 2$ sites respectively. To construct phag-lacZ, a DNA fragment of $361 \mathrm{bp}(-189$ to +172$)$ containing the hag promoter and the first 27 codons of the hag ORF (Mirel \& Chamberlin, 1989) was cloned in translational frame to the E. coli lacZ gene in the replicative multi-copy plasmid pRB381 (Table 1) (Bruckner, 1992). The constructs phaglacZ- $\mathrm{H}_{\mathrm{P}}$ and phag-lacZ- $\mathrm{H}_{\mathrm{Q}}$ were identical to phag-lacZ in all respects except for the mutation in the $\mathrm{H} 1\left(\mathrm{H}_{\mathrm{P}}\right)$ or $\mathrm{H} 2$ $\left(\mathrm{H}_{\mathrm{Q}}\right)$ site, respectively. Unlike $\mathrm{H}_{\mathrm{A}}$, in which all the bases of $\mathrm{H} 1$ were mutated and which was used for the binding experiments with ScoC, the $\mathrm{H}_{\mathrm{P}}$ site in phag-lacZ- $\mathrm{H}_{\mathrm{P}}$ contained mutations in only four bases from the $3^{\prime}$-end of H1 (5'-GATATAGGG-3'). This was done so as to keep the
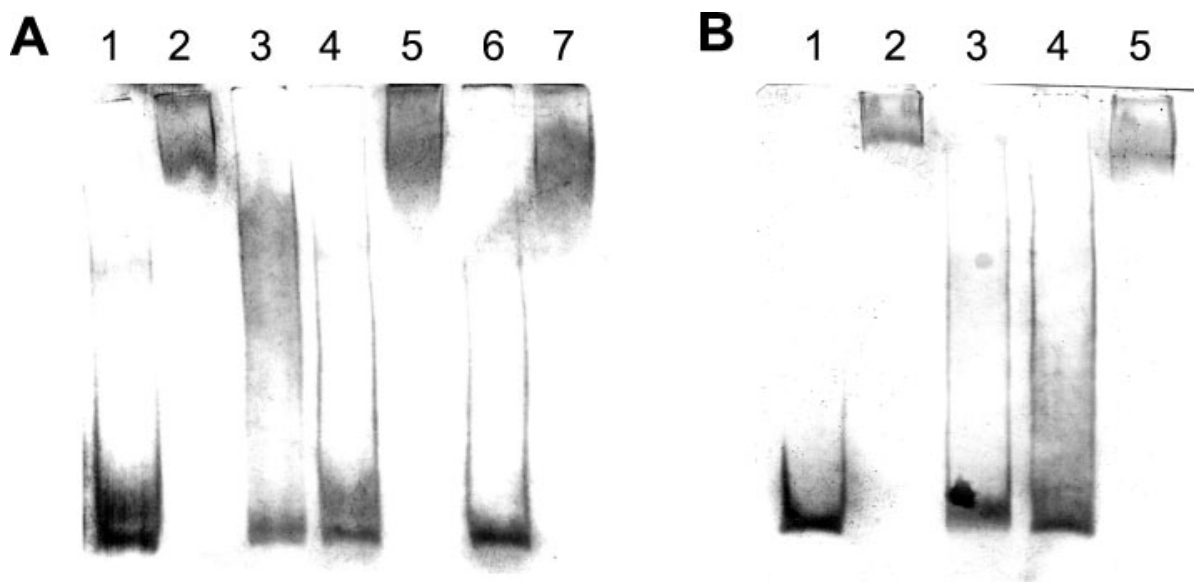

Fig. 2. (A) EMSA of ScoC with DIG-labelled hag probe containing $\mathrm{H} 1$ or $\mathrm{H}_{\mathrm{A}}$ or $\mathrm{H}_{\mathrm{P}}$ sites. See Methods for details of the assay conditions. Lanes: 1 , labelled $\mathrm{H} 1 ; 2$, labelled $\mathrm{H} 1+\mathrm{ScoC}$; 3 , labelled $\mathrm{H} 1+\mathrm{ScoC}+100 \times$ unlabelled $\mathrm{H} 1 ; 4$, labelled $\mathrm{H}_{\mathrm{A}}+\mathrm{ScoC}$; 5 , labelled $\mathrm{H} 1+\mathrm{ScoC}+100 \times$ unlabelled $\mathrm{H}_{\mathrm{A}} ; 6$, labelled $\mathrm{H}_{\mathrm{P}}+\mathrm{ScoC} ; 7$, labelled $\mathrm{H} 1+\mathrm{ScoC}+100 \times$ unlabelled $\mathrm{H}_{\mathrm{P}}$. (B) EMSA of ScoC with DIG-labelled hag probe containing $\mathrm{H} 2$ and $\mathrm{H}_{\mathrm{Q}}$ sites. Lanes: 1, labelled $\mathrm{H} 2 ; 2$, labelled $\mathrm{H} 2+\mathrm{ScoC} ; 3$, labelled $\mathrm{H} 2+\mathrm{ScoC}+100 \times$ unlabelled $\mathrm{H}_{2} ; 4$, labelled $\mathrm{H}_{\mathrm{Q}}+\mathrm{ScoC} ; 5$, labelled $\mathrm{H} 2+\mathrm{ScoC}+100 \times$ unlabelled $\mathrm{H}_{\mathrm{Q}}$. 
-10 sequence of the promoter intact (Fig. 1). Binding studies confirmed that, similar to $\mathrm{H}_{\mathrm{A}}$, ScoC is unable to bind $\mathrm{H}_{\mathrm{P}}$ (Fig. 2A, lane 6) and the partially mutated probe could not compete for binding of ScoC to the wild-type probe (Fig. 2A, lane 7).

The two plasmids, phag-lacZ- $\mathrm{H}_{\mathrm{P}}$ and phag-lacZ- $\mathrm{H}_{\mathrm{Q}}$, were introduced into B. subtilis 168 to give $168 /$ phag-lacZ- $\mathrm{H}_{\mathrm{P}}$ and 168/phag-lacZ- $\mathrm{H}_{\mathrm{Q}}$ (Table 1) and the promoter activities were compared with that in 168/phag-lacZ (phag-lacZ in B. subtilis 168, Table 1). The promoter activities in $168 /$ phag-lacZ- $\mathrm{H}_{\mathrm{P}}$ and 168 /phag-lacZ- $\mathrm{H}_{\mathrm{Q}}$ were $16500 \pm 150$ and $17000 \pm 150$ Miller units, respectively, as compared to $2000 \pm 50$ Miller units in 168/phag-lacZ (Table $3 \mathrm{~B}$ ), clearly indicating that the mutation of either the $\mathrm{H} 1$ or the $\mathrm{H} 2$ site led to loss of repression.

The level of relief from repression upon mutation of either the $\mathrm{H} 1$ or the $\mathrm{H} 2$ site was almost eightfold higher as compared to a twofold relief in 168scoC: hag'-lacZ. Similar twofold relief was observed when the multicopy plasmid phag-lacZ was introduced into $168 \mathrm{scoC}$ and hag reporter expression was compared with that in 168/phag-lacZ (data not shown). This suggested to us that hag is subject to both negative and positive regulation and that in $168 \mathrm{scoC}$ : hag' lacZ the extent of relief in repression is blunted by the loss of positive regulation.

Based on the transcription profiling of $s c o C 4$, in which motility genes were shown to be downregulated, it was proposed that ScoC positively regulates the availability of $\sigma^{\mathrm{D}}$ by downregulating FlgM activity (Caldwell et al., 2001). FlgM has previously been shown to be a negative regulator of hag expression (Fredrick \& Helmann, 1996). We confirmed that FlgM indeed negatively regulates hag transcription by measuring hag expression in an flgM mutant background (1A764, Table 1) and compared its activity with that in the isogenic wild-type strain, JH642 (Table 1). We measured the effect of FlgM on hag expression in the JH642 background instead of in the 168 background, avoiding intricacies of moving the in-frame flgM deletion into 168 without any selectable marker, since strain 1A764, an flgM mutant, was created by deleting 80 of the 88 amino acids in the FlgM ORF (Mirel et al., 1994). The plasmid phag-lacZ was introduced into B. subtilis JH642 and B. subtilis 1A764 to give JH642/phag-lacZ and 1A764/phag-lacZ (Table 1), respectively, and the promoter activities were determined. The $\beta$-galactosidase activity in 1A764/phag-lacZ was $3700 \pm 50$ Miller units, more than twofold higher as compared to JH642/phag-lacZ $(1700 \pm 25$ Miller units; Table 3C). A similar increase in hag promoter activity in the flgM mutant background was previously reported by Fredrick \& Helmann (1996).

\section{flgM is transcriptionally regulated by ScoC}

To show experimentally that ScoC downregulates FlgM, we assessed flgM transcription in wild-type B. subtilis 168 and $168 \mathrm{scoC}$. flgM is the second gene of an operon that contains four ORFs, $y v y F$ (orf 139), flgM, yvyG (orf 160) and $f l g K$, and is transcribed from a single promoter, $\mathrm{P}_{\mathrm{D}-1}$ (Mirel et al., 1994). The $\mathrm{P}_{\mathrm{D}-1}$ promoter and the ATG of $y v y F$ (hereafter referred to as the flgM promoter) was cloned in translational frame with the E. coli lacZ gene in pRB381 (Bruckner, 1992) to give plasmid pflgM-lacZ (Table 1). pflgM-lacZ was transformed into B. subtilis 168 and $168 \mathrm{scoC}$ to yield $168 / \mathrm{pflgM}-\mathrm{lacZ}$ and $168 \mathrm{scoC} / \mathrm{pflgM}-$ lacZ (Table 1) and the $\beta$-galactosidase activities were determined (Nicholson \& Setlow, 1990) between $4 \mathrm{~h}\left(t_{0}\right)$ and $6 \mathrm{~h}\left(t_{2}\right)$ of growth $\left(t_{0}\right.$ corresponds to entry into stationary phase), as flgM expression has been observed to be maximal during this stage of growth (Liu \& Zuber, 1998). The growth rates of both strains were identical. The promoter activity in $168 \mathrm{scoC} / \mathrm{pflgM}-\mathrm{lacZ}$ was at least twice that in 168/pflgM-lacZ (Fig. 3), indicating that ScoC negatively regulates $\mathrm{flgM}$ expression. The increase in expression of flgM in $168 \mathrm{scoC}$ is also reflected in the levels of FlgM protein as determined by Western blot analysis using polyclonal anti-FlgM antibodies raised against purified FlgM. Fig. 4(B) shows that the level of FlgM is at least two to three times higher in $168 \mathrm{scoC}$ as compared to that in wild-type cells when measured at $5 \mathrm{~h}\left(t_{1}\right)$ and $6 \mathrm{~h}$ $\left(t_{2}\right)$. We conclude that the negative regulation of $f \lg M$ is also reflected in the levels of the FlgM protein. These results thus provide experimental support that ScoC positively regulates hag expression by downregulating the levels of FlgM, leading to enhanced $\sigma^{\mathrm{D}}$ activity. The fourfold difference observed between the relief from repression when either of the sites is mutated and the relief in repression in $168 \mathrm{scoC}$ : hag'-lacZ also suggests that positive regulation of hag by ScoC predominates.

If this were the case we reasoned that if ScoC was introduced on a multi-copy plasmid in wild-type cells, then the hag promoter activity should be higher than in cells carrying a single copy. For this purpose, B. subtilis 168 was transformed with a multi-copy plasmid, pIC-scoC

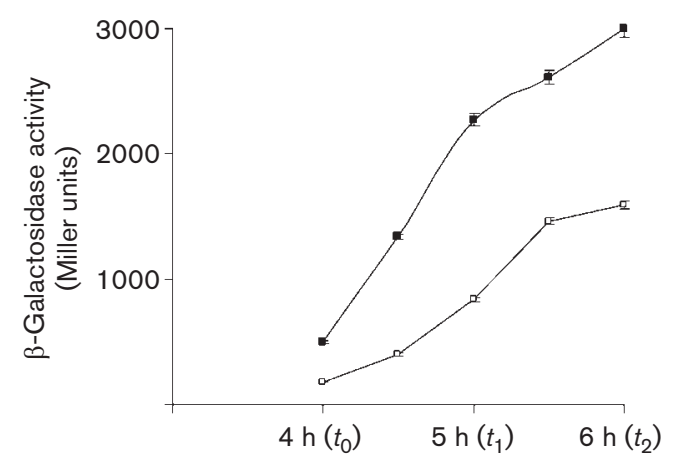

Fig. 3. $f l g M$ reporter expression in $B$. subtilis $168 /$ pflgM-lac $Z$ ( $\square$ ) and $168 \mathrm{scoC} / \mathrm{pflgM}-\mathrm{lacZ}(\boldsymbol{\square}) . t_{0}$ is the time of entry into stationary phase. Data shown (means \pm SE from triplicate values) are from a representative experiment of at least three independent experiments. 
A

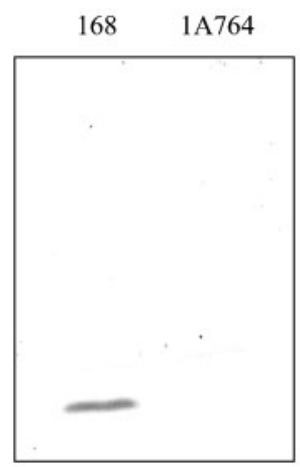

B

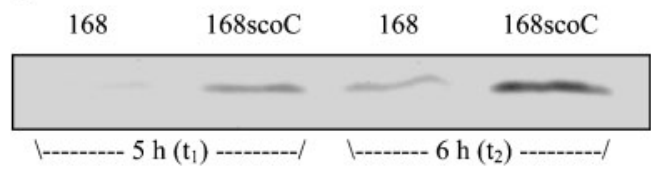

Fig. 4. (A) Confirmation of anti-FlgM specificity of anti-FlgM polyclonal antibodies by Western blot analysis of $B$. subtilis 168 and $1 \mathrm{~A} 764$ (flgM mutant). (B) Detection of FlgM in B. subtilis 168 and $168 \mathrm{scoC}$.

(Table 1), encoding ScoC, to give $168: \mathrm{hag}^{\prime}$-lacZ/pIC-scoC, and the promoter activity of hag was compared with that in 168 : hag'-lacZ. The hag promoter activity of $168:$ hag $^{\prime}-$ lacZ/pIC-scoC was $410 \pm 20$ Miller units and was twice that of 168 : hag'-lacZ (225 \pm 10 Miller units) (Table 3A). This clearly supports the contention that the positive effect of ScoC is predominant.

\section{DISCUSSION}

Transcription profiling has shown that 29 out of 55 motility and chemotaxis genes are affected by the transition state regulator ScoC (Caldwell et al., 2001). This is a testament to the crucial role played by ScoC in the regulation of motility genes in $B$. subtilis. To date, the exact mechanism for this regulation is not known, although it was thought that ScoC regulates these genes by indirectly regulating the availability of $\sigma^{\mathrm{D}}$ via a pathway that involves SinR (Caldwell et al., 2001). SinR is expressed from a dicistronic operon, $\operatorname{sinIR}$. The product of the first gene, SinI, post-translationally antagonizes the activity of $\operatorname{SinR}$ by converting SinR from its active tetrameric state to an inactive SinI-SinR heterodimer. ScoC represses sinI transcription (Kallio et al., 1991; Shafikhani et al., 2002), resulting in elevated levels of active SinR and thus leading to increased levels of $\sigma^{\mathrm{D}}$ (Caldwell et al., 2001), probably via decreasing FlgM activity. This model is supported by the observation that deletion of flgM could restore motility in a $\sin R$ null mutant (Fredrick \& Helmann, 1996). However, we have demonstrated that ScoC downregulates FlgM and thereby positively controls the availability of $\sigma^{\mathrm{D}}$ and therefore motility gene expression.
Our observation that $\mathrm{ScoC}$ is a repressor of hag expression is contrary to the report of Caldwell et al. (2001), wherein, from transcriptional profiling experiments, they reported decreased hag expression in a $s c o C$ mutant background. In general microarray results are quite reliable; however, accurate measurement of absolute expression levels is often not possible for various reasons such as suboptimal design or choice of probes, inconsistent sequence fidelity of the spotted microarrays, variability of differential expression and discrepancy in fold-change calculation (Kothapalli et al., 2002; Draghici et al., 2006). Our results clearly suggest that ScoC specifically binds to two sites in the hag promoter region and that repression of hag is relieved in the absence of ScoC. The presence of two ScoC binding sites in the hag promoter region suggests that, as in the case of the nprE, aprE and sinI promoters (Kallio et al., 1991), ScoC may manifest its function through the formation of a bent repression loop as proposed by several investigators (Smith, 1993; Strauch \& Hoch, 1992, 1993), thereby affecting promoter clearance. In addition ScoC may regulate transcription initiation of hag by preventing open complex formation, as the $\mathrm{H} 1$ site overlaps with the -10 region of the promoter (Fig. 1). CodY, another regulator of hag, monitors the general nutritional state of the cell by sensing intracellular GTP levels (Fisher, 1999; RatnayakeLecamwasam et al., 2001). It is known to repress hag expression in rich media, and repression of hag is relieved approximately twofold in a $\operatorname{cod} Y$ mutant background. Interestingly, the $\mathrm{H} 2$ site of hag overlaps with the CodY binding site (Bergara et al., 2003). Therefore, it is possible that mutation of $\mathrm{H} 2$ might affect the binding of CodY to the hag promoter region and additionally contribute to the relief in repression of hag.

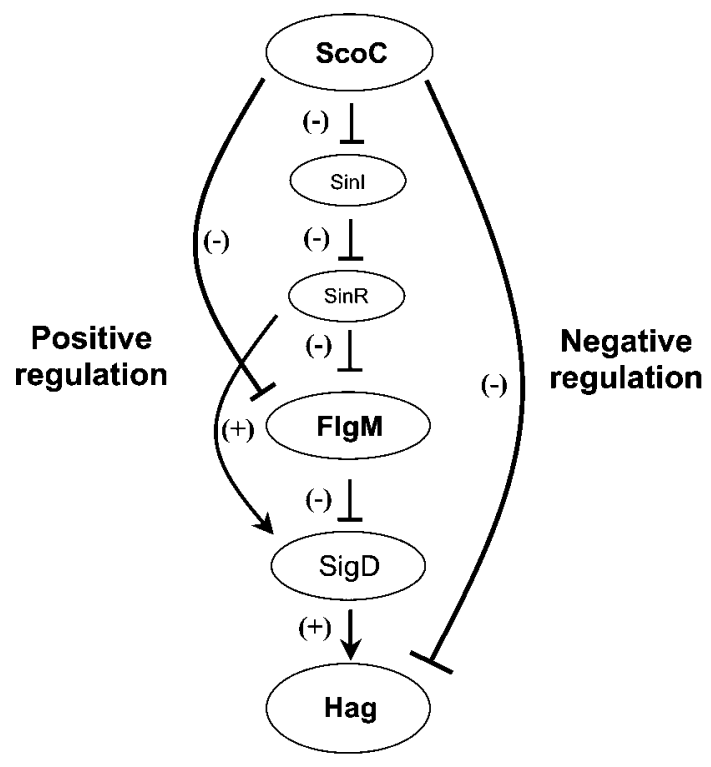

Fig. 5. Model for hag regulation by ScoC in B. subtilis. 
The difference in the extent of relief from repression in $168 \mathrm{scoC}$ as compared to that in $168 /$ phag-lacZ- $\mathrm{H}_{\mathrm{P}}$ and $168 /$ phag-lacZ- $\mathrm{H}_{\mathrm{Q}}$ suggests that hag transcription is both negatively and positively regulated by ScoC. The positive regulation is manifested by increased availability of $\sigma^{\mathrm{D}}$ as a result of decreased levels of FlgM. A model for hag regulation is presented in Fig. 5. We envisage that such a dual control by ScoC is most likely aimed at 'fine-tuning' hag expression levels to suit the cell's needs in different environmental conditions, such as efficient nutrient acquisition, avoidance of toxic substances, translocation to optimal colonization sites and dispersal in the environment.

\section{ACKNOWLEDGEMENTS}

P. K. acknowledges the Council for Scientific and Industrial Research, India, for a $\mathrm{PhD}$ research fellowship [9/87(328)/2003-EMR-I]. We thank U. Storb for valuable suggestions concerning the manuscript.

\section{REFERENCES}

Bergara, F., Ibarra, C., Iwamasa, J., Patarroyo, J. C., Aguilera, R. \& Marquez-Magana, L. M. (2003). CodY is a nutritional repressor of flagellar gene expression in Bacillus subtilis. J Bacteriol 185, 31183126.

Bertero, M. G., Gonzales, B., Tarricone, C., Ceciliani, F. \& Galizzi, A. (1999). Overproduction and characterization of the Bacillus subtilis anti-sigma factor FlgM. J Biol Chem 274, 12103-12107.

Bron, S. (1990). Plasmids. In Molecular Biological Methods for Bacillus, pp. 75-139. Edited by C. R. Harwood \& S. M. Cutting. New York: Wiley.

Bruckner, R. (1992). A series of shuttle vectors for Bacillus subtilis and Escherichia coli. Gene 122, 187-192.

Caldwell, R., Sapolsky, R., Weyler, W., Maile, R. R., Causey, S. C. \& Ferrari, E. (2001). Correlation between Bacillus subtilis scoC phenotype and gene expression determined using microarrays for transcriptome analysis. J Bacteriol 183, 7329-7340.

Draghici, S., Khatri, P., Eklund, A. C. \& Szallasi, Z. (2006). Reliability and reproducibility issues in DNA microarray measurements. Trends Genet 22, 101-109.

Fisher, S. H. (1999). Regulation of nitrogen metabolism in Bacillus subtilis: vive la difference! Mol Microbiol 32, 223-232.

Fredrick, K. \& Helmann, J. D. (1996). FlgM is a primary regulator of $\sigma^{\mathrm{D}}$ activity, and its absence restores motility to a $\sin R$ mutant. $J$ Bacteriol 178, 7010-7013.

Hecker, M. \& Volker, U. (1998). Non-specific, general and multiple stress resistance of growth-restricted Bacillus subtilis cells by the expression of the $\sigma^{\mathrm{B}}$ regulon. Mol Microbiol 29, 1129-1136.

Helmann, J. D. (1999). Anti-sigma factors. Curr Opin Microbiol 2, 135-141.

Henner, D. J., Ferrari, E., Perego, M. \& Hoch, J. A. (1988). Location of the targets of the hpr-97, sacU32(Hy), and sacQ36(Hy) mutations in upstream regions of the subtilisin promoter. J Bacteriol 170, 296-300.

Hughes, K. T. \& Mathee, K. (1998). The anti-sigma factors. Annu Rev Microbiol 52, 231-286.

Kallio, P. T., Fagelson, J. E., Hoch, J. A. \& Strauch, M. A. (1991). The transition state regulator Hpr of Bacillus subtilis is a DNA-binding protein. J Biol Chem 266, 13411-13417.
Kodgire, P., Dixit, M. \& Rao, K. K. (2006). ScoC and SinR negatively regulate epr by corepression in Bacillus subtilis. J Bacteriol 188, 64256428.

Kothapalli, R., Yoder, S. J., Mane, S. \& Loughran, T. P., Jr (2002). Microarray results: how accurate are they? BMC Bioinformatics 3, 22.

Liu, J. \& Zuber, P. (1998). A molecular switch controlling competence and motility: competence regulatory factors ComS, MecA, and ComK control $\sigma^{\mathrm{D}}$-dependent gene expression in Bacillus subtilis. J Bacteriol 180, 4243-4251.

Mirel, D. B. \& Chamberlin, M. J. (1989). The Bacillus subtilis flagellin gene (hag) is transcribed by the $\sigma^{28}$ form of RNA polymerase. $J$ Bacteriol 171, 3095-3101.

Mirel, D. B., Lauer, P. \& Chamberlin, M. J. (1994). Identification of flagellar synthesis regulatory and structural genes in a $\sigma^{\mathrm{D}}$-dependent operon of Bacillus subtilis. J Bacteriol 176, 4492-4500.

Mirel, D. B., Estacio, W. F., Mathieu, M., Olmsted, E., Ramirez, J. \& Marquez-Magana, L. M. (2000). Environmental regulation of Bacillus subtilis $\sigma^{\mathrm{D}}$-dependent gene expression. J Bacteriol 182, 3055-3062.

Nicholson, W. L. \& Setlow, P. (1990). Sporulation, germination, and outgrowth. In Molecular Biological Methods for Bacillus, pp. 442-444. Edited by C. R. Harwood \& S. M. Cutting. New York: Wiley.

Ordal, G. W., Márquez-Magaña, L. M. \& Chamberlin, M. J. (1993). Motility and Chemotaxis. In Bacillus subtilis and Other Gram-positive Bacteria: Biochemistry, Physiology, and Molecular Genetics, pp. 765784. Edited by A. L. Sonenshein, J. A. Hoch \& R. Losick. Washington, DC: American Society for Microbiology.

Perego, M. \& Hoch, J. A. (1988). Sequence analysis and regulation of the $h p r$ locus, a regulatory gene for protease production and sporulation in Bacillus subtilis. J Bacteriol 170, 2560-2567.

Ratnayake-Lecamwasam, M., Serror, P., Wong, K. W. \& Sonenshein, A. L. (2001). Bacillus subtilis CodY represses early-stationary-phase genes by sensing GTP levels. Genes Dev 15, 1093-1103.

Sambrook, J., Fritsh, E. F. \& Maniatis, T. (1989). Molecular Cloning: $a$ Laboratory Manual. Cold Spring Harbor, NY: Cold Spring Harbor Laboratory.

Shafikhani, S. H., Mandic-Mulec, I., Strauch, M. A., Smith, I. \& Leighton, T. (2002). Postexponential regulation of sin operon expression in Bacillus subtilis. J Bacteriol 184, 564-571.

Smith, I. (1993). Regulatory proteins that control late-growth developement. In Bacillus subtilis and Other Gram-positive Bacteria: Biochemistry, Physiology, and Molecular Genetics, pp. 785-800. Edited by A. L. Sonenshein, J. A. Hoch \& R. Losick. Washington, DC: American Society for Microbiology.

Steinmetz, M. \& Richter, R. (1994). Plasmids designed to alter the antibiotic resistance expressed by insertion mutations in Bacillus subtilis, through in vivo recombination. Gene 142, 79-83.

Strauch, M. A. \& Hoch, J. A. (1992). Control of postexponential gene expression by transition state regulators. In Biology of Bacilli: Application to Industry, pp. 105-121. Edited by R. H. Doi \& M. McGloughlin. Stoneham, MA: Butterworth-Heinemann.

Strauch, M. A. \& Hoch, J. A. (1993). Transition-state regulators: sentinels of Bacillus subtilis post-exponential gene expression. Mol Microbiol 7, 337-342.

Strauch, M. A., Spiegelman, G. B., Perego, M., Johnson, W. C., Burbulys, D. \& Hoch, J. A. (1989). The transition state transcription regulator abrB of Bacillus subtilis is a DNA binding protein. EMBO J 8, 1615-1621.

Vagner, V., Dervyn, E. \& Ehrlich, S. D. (1998). A vector for systematic gene inactivation in Bacillus subtilis. Microbiology 144, 3097-3104.

Edited by: T. Msadek 